\title{
The Bitter Fruit of Power. An Ethnographic Study of Corporate Compliance
}

\author{
Davide Torsello \\ CEU Business School, Hungary
}

Compliance is a field that has recently achieved increasing complexity and significance in business. This paper addresses the issue of how compliance mechanisms are negotiated and accepted within corporations I will present the results of ethnographic research conducted with six compliance officers from five companies located in Hungary. I will argue that due to their task, as well as to the social and cultural features of business in the region, compliance officers are gaining increased power that needs to be negotiated in ways that sometimes endanger the actual objectives of corporate compliance.

\section{INTRODUCTION}

This paper addresses the issue of how compliance mechanisms and managerial positions are negotiated and accepted within corporations within a global panorama of increased concern for business integrity. I will show that although the importance of corporate compliance has significantly increased over the last years, compliance and integrity still play rather marginal roles within companies' management goals. This is not simply due to, as much of the literature in business ethics suggest, the difficult coexistence of integrity and ethics with the traditional prioritization on profit making. I will argue that the paradox which compliance faces is that although increasing complexity of national and international anti-corruption legislative measures requires corporations to establish in-house compliance department, compliance officers strive to negotiate legitimacy in their daily tasks at their workplaces. This creates an imbalance between a condition of increasing power of the compliance officers in the company and a business environment often unprepared to the rationality and impartiality prerequisites on which compliance is grounded. In particular, compliance mechanisms are under pressures from conditions of poor generalized trust, informality and suspicion in transition market economies.

In the first part of the paper I focus on the development of compliance programs in business and on some of the theoretical foundations on which business ethics has developed as an autonomous academic field of study. In the second part I present my ethnographic data on the study of compliance in five companies, focusing on the features of the compliance officer work profile, on the interactional and communicative strategies and challenges that this figure encounter in the company.

\section{THE ORIGIN OF CORPORATE COMPLIANCE}

Compliance is commonly defined in business as "being in accordance with established guidelines, specifications, or legislation, or the process of becoming so" (SearchDataManagement.com 2008). This is no more than a working definition that leaves little space to a clear understanding of the complexity of roles and tasks of the compliance officers. It is not clear when in history compliance has come to play an 
important role in business, some sources point at the beginning of the $20^{\text {th }}$ Century, when regulatory bodies were introduced to set limits to the expanding scope of business and in particularly to its effects to public safety. One of these bodies was, in the US, the Food and Drug Administration, founded in 1906, with the aim of safeguarding against hazardous food and drug products and derivates. At the beginning of the $20^{\text {th }}$ Century several of these institutions flourished in US and Europe, but the most common approach was still that compliance with state regulations over business pertained to the public domain. Most of the ruling bodies were, thus, enforced publicly and did not have a direct connection with the business world (Watson 2004, Baer 2009).

The conditions under which compliance developed changed almost abruptly towards the mid-1970s. Following repeated world scandals of corruption, that followed the Watergate stream, there was a widespread concern that the nexus between business and the public sphere had become rotten from its very foundations. Investigations, conducted most conspicuously in the US, led to the discovery of hundreds of US firms that used to pay bribes to foreign and domestic officials to win bids and contracts. Business discovered itself, in all its vehemence, to be unethical and unaccountable, as scandals peaked over the US Ministry of Defense. At least in this country the watershed towards the new role of business compliance became the 1977 Foreign Corrupt Practices Act (FCPA) that set the milestones for regulating ethical business behavior abroad. Among the prescriptions of FCPA was that companies were expected to have in place adequate systems of internal accounting controls, paving the way to the need of establishing compliance mechanisms internal to the companies and not as public entities. It took 20 years until the US Congress extended these efforts to the international arena, obtaining ratification by OECD countries of the Convention on Combating Bribery of Foreign Public Officials in International Business Transactions (1997).

The most significant development for the history of compliance in the US, however, has been the enactment of the US Sentencing Guidelines, created by the Sentencing Reform Act (1984). These, in particular under the revision of 2010, clearly defined the importance of compliance programs and mechanisms within companies. The most innovative introduction has been the decision that a convicted corporation is eligible for a reduced sentence if it had an effective compliance and ethics program in place at the time of the offence. Apart from the guidelines that delineate how this program should be considered as effective, it is remarkable that by 2010 US companies only rarely qualified for sentence reductions because in most cases they did not have any compliance and ethics programs. The situation is even worse in the case of Europe, where apart from the recent UK Bribery Act (2011) and the EU Framework Decision on Combating Corruption in the Private Sector $(2003,2011)$ have showed a much more fragmented and still developing response to the need for corporate compliance.

\section{HOW ETHICAL CAN BUSINESS BE?}

The recent greater emphasis on compliance has mostly come from the implementation of national and international legislative measures in the US, UK and partly by the EU. If typically companies did not have any forms and programs of compliance active in their organizational structures, today it has become increasingly important to have them, for a number of reasons. The question is: how this increased emphasis on compliance relates to the changing theoretical paradigms on business ethics?

Business ethics has developed as an autonomous academic field not earlier than the 1970s. Again, following the crises and scandals that in several fields (financial, environmental, human rights violations and in connection with the war industry) interested large multinationals, there emerged an interdisciplinary interest in ethics applied to business (Tsalikis and Fritzsche 1989, Randall and Gibson 1990, Bartlett 2003, Trevino and Nelson 2004, Waddock 2006). This had, in the early years, a two-faced expression. On the one hand, as corporations strengthened their involvement in social responsibility, the field of corporate social responsibility became to thrive, producing a progressively booming literature in the many aspects of CSR involvement (Cortina 2008). Within CSR, however, no systematic attention was posed on ethical behavior of companies, and the field of integrity remained almost an unpaved way. 
On the other hand, it was the work of a number of philosophers in the business field that paved the way to the field of ethics. Business ethics mainly emerged as the intersection of ethical theory in philosophy and its application to a number of practical cases (De George 1990). According to De George, what differentiated business ethics from other social issues in management is: 1) unlike in CSR, ethics were set as a theoretical framework which is independent from business, and 2) the field was more critical to business practices than CSR could never achieve. Business ethics specialists, in a way, could be seen as potential antagonists of marketing experts, because of their concern with setting limits to unethical business and justifying needs for compliance paradigms in the formal respect for institutional regulations and laws. On the other hand, CSR can easily be waved as a weapon or showcases of good social performance in corporate business.

(http://www.scu.edu/ethics/practicing/focusareas/business/conference/presentations/business-ethicshistory.html, accessed on 4-6-2013).

In a recent review of the research trends Brenkert (2010) points out that increase of studies and research in the field of business ethics runs in parallel with the increase of scandals of business corruption over the last four decades. This has produced a generally increased and rapid theoretical sophistication of the field of business ethics, which has not been matched by the compliance with ethical requirements and integrity strategies by the business world. Brenkert finds two orders of explanation to this mismatch. First, much of the business ethics field has been embracing what he defines as "rational arguments", which focus on the classical homo oeconomicus approach that seeks individualistic profit-maximization. The first problem is that the way rationality is viewed by some business ethicists is almost coincident with that of neoclassical economists, and hence this position is of little help to the diversification of ethical behavior and management strategy (Benkert 2010: 705).

The second problem relates to the contexts in which ethical business should root. Here, as the rapid and multifaceted development of CSR scholarship has proved, there are no easy agreements on how business can set moral standards that are recognizable in societies, and where these standards can be applied. History, and the overall number of corruption scandals in public procurement, has demonstrated that governments are no easy and healthy domains in which establishing ethical business practices. If governments remain essential to improve corporate behavior (Vogel 2005), it remains unclear whether more complex regulations can actually help business to achieve a "less egoistic" character. This happens in the lights of recent development such as global financial crises, the growing importance of shareholders and the decreasing importance of stakeholders, increased vulnerability of smaller companies to global competition, and the coexistence of different socio-cultural forms moralities (Pardo 2004, Torsello 2012).

\section{METHODOLOGY AND SETTING}

Ethnographic research methods have been developed in the field of anthropology. The most common methods include participant observation, selected interviews, shadowing, focus groups and survey questionnaires. There are positive and negative features in the use of each of these techniques, as recognized in the field of anthropology and other social science disciplines that have in recent times adopted ethnographic methods (Schensul et al.1999, Sharpe 2004, Moeran 2005). The importance of anthropological research, and of the application of its methods to business has found momentum over the last years (Cefkin 2010, Jordan 2010, Marrewijk 2010, Tian et.al. 2010, Tian et al. 2011).

In the case of this research selected interviews was the chosen method. This methodology was constrained by the sensibility of the issues being debated with the interviewed, which led me to adopt full anonymity of informants as well as of the companies who agreed to take part in the research. I will use, throughout the paper, fictive names, but correspondent gender and age indications, whereas companies will not be named.

This research is based on interviews conducted with six compliance officers of five companies, all located in Hungary, in the period between September 2011 and April 2012. Four of the companies are multinationals, and one a small company established in 2010. Three of the interviewed were male and three female, their average age is in the range $28-35$, so they are all distinctively young officers. In the 
course of my interviews I was confronted with a number of ethical and methodological issues, which are very common in ethnographic research. I will summarize three of them. The first is data exposure: I became aware that the best strategy in order to establish trust with the interviewed persons, who represented a company and did not act as single professionals, was to maintain secrecy on the identity of the other persons being interviewed and particularly on their companies. This avoided the natural resiliency to disclose any sort of sensitive information that might have been used by others participating in the interviews.

Secondly, in order to provide both confidentiality of information, and a positive outcome of the research, I decided to formulate a number of point on which the interview was going to focus and to distribute them beforehand to the interviewees. This choice had the benefit of structuring the interview and also of giving the participants time to prepare on the topics being covered.

The third point concerns the use of case studies. As I was going to interview compliance personnel who are exposed to cases of fraud and misconduct in the companies in which they operate, as well as to knowledge of such cases in other companies, I was unsure on how to deal with the delicate issue of using cases to communicate with company personnel. After conducting the first two interviews I became aware that I could not easily get access to those cases which the compliance officers use in their training and regular job activities. Thus, rather than learning on these cases I decided to focus on their perceived applicability as well as on the training methodology that their use require.

Moreover, an issue that resulted of primary importance in assessing the usefulness of case studies in corruption and fraud scandals was the conditions under which compliance mechanisms were put in place in the companies. Only in one case an officer referred expressively to a corruption scandal for which her company was convicted and hence set to establish a compliance program. Among the five companies, three followed the same path, hiring compliance officers due to past convictions or investigations.

Finally, the issue of the region in which companies are located is of great importance. As mentioned above, corporate compliance mechanisms have been developed in the Northern American contexts, and as such are not easily applicable to different business culture backgrounds (Ardichvili and Jondle 2009, Shakeel et al. 2011). For one thing, the pressure that the US Congress has exerted towards the international recognition of its FCPA and related measure is telling of the actual discrepancy between countries and corporate cultures in which business integrity can more or less easily become a domain of public or governmental debate. Hungary, the most economically dynamic Eastern European country in the immediate postsocialist years in terms of foreign investment and liberalization policies, is today facing a long recession that has seriously affected this record.

Not dissimilarly from other European countries of the former socialist bloc, the rapidity and profound changes brought about in the 1990s have profoundly affected social values to the point of making generalized trust a costly option (Torsello 2003). Trust has assumed preeminence giving strength to informal agreement and practices, as the remains of the previous regime were collapsing replaced by chaotic capitalism and the aggressive attack of multinationals. It is not a surprise if, still today, each of the interviewed compliance officers had at least one remark on the importance and difficulty of building trust relations in their work environment, and on the fragility of their tasks because of this demand.

\section{INSIDE THE COMPLIANCE OFFICER PROFILE}

One starting point of this research has been to analyze the profile of the compliance officer. Unexpectedly, the first finding is that only one on six had an educational background in legal studies. Pal (28 years), before working in his bank as CCO (Chief Compliance Officer) graduated in law and worked as an advisor for the Ministry of Justice. He "saw things from both sides", even though he was unready to admit whether staying on the government or on the private side was better. One thing he recognized, however, is that being a lawyer is not always such rosy an option, because "people in business see lawyers as distant entities". This remark matches with the idea that legal actions and auditing processes are often undertaken more efficiently out of the company departments or through external consultancy due to the need to keep sensitive information confidential (Watson 2004). 
All the interviewees agreed on two points that better specify the profile of this job task. The first concerns the way in which knowledge of the job is achieved, that is "on the job" rather than by training. Two interviewed officers had received formal training in compliance, one in a mid-size company and another in a multinational, as a trainee in a foreign branch. Both of them, however, admitted that the experience learned on the job was usually much more relevant to their daily tasks. This was indicated, on the one hand, in relation to the opportunity to get a better understanding of the tasks and roles by doing, i.e. the practical aspect of compliance. On the other hand, learning on the job was seen as the optimal solution because it grants a "vision of the interests of all the stakeholders", which can be interpreted as a through understanding of roles, competencies and motivations of the company members. As a matter of fact, those officers who did not receive any formal training in compliance, as they were mostly paired or coached by senior officers for relatively short periods, were not ready to admit that they missed other forms of training.

The second point concerns the relational aspect of their tasks. Although in 4 on 6 cases respondents manifested an open concern for the "rational" aspect of their duty, the fact that compliance mechanisms operate only in contexts of social interactions, and are not market or profit-driven, has been acknowledged more ore less openly by all officers.

Katalin (33) said: "our contribution needs to be structured in all we do, otherwise we fail", and Margit (36 years old) stressed that: "strategy must be communicated first, and then come the single cases". On the other side of the rational-relational dichotomy, as presented by Katalin herself, all respondents underlined the importance of developing socializing and emotionally sensitive skills such as empathy, trustworthiness and respect in their work environment. The idea that compliance officers are too often seen as "policemen" dominated many of the conversations and it was, in the end, more a metaphor for indicating the crucial importance of relational skills rather than a pessimistic view of the usefulness of compliance.

\section{BUILDING AND NEGOTIATING POWER THROUGH INTERPERSONAL RELATIONS}

The two features that best characterize the profile of compliance officers, i.e. becoming experienced on the job and possessing a balanced dose of relational skills and impartiality, easily translate into strategic ways how to build and negotiate power within companies. Anthropology has been among the social science disciplines one of the most attentive to describe micro-level strategies of power-building in different contexts, and above all to pay attention to the socially informed mechanisms through which power is negotiated, contrasted or legitimized (Gledhill 2000, Kurtz 2001). Among theorists, Eric Wolf has been one of the strongest advocators of a multidimensional approach to the study of power.

According to Wolf, power is not simply expressed through the possibility that others will comply with indications or orders from above, but it must be constructed at four levels. These are: power attributed to the single, meaning his potential capacity to exert it; the ability of a person to impose power within a social relationship; the environment in which power relations are constructed; and the distribution and direction of energy fluxes which structure the environment (Wolf 2002: 223). In this perspective, in order to understand the changing role of compliance officers in corporate settings, one needs to pay attention not only to how their profile and tasks are set in the company, but more importantly, to how the nesting of intra-firm relationship, as well as the working environment contribute to shape new forms of power. This latter aim will be achieved here by focusing on two aspects: the relational, i.e. the ways in which compliance officers manage their increased power by relating with managers, and the communication strategies through which the tasks of compliance are legitimated within companies.

Concerning the relational aspect, one issue that emerged in all interviews was that increasingly perceived power of compliance officers within their companies is felt in the daily space of personal interactions. Because of the reporting system, compliance officers are in a sensitive position of having, both access to confidential information, and the need to report on this to C-level managers and in some cases to the board. This point has been emphasized in the relevant literature on compliance (Watson 2003, Compliance Week 2012), in particularly concerning the interlocutors of the reports. In a survey dated 
2011 (The State of Compliance Study), it has emerged that in the US, $41 \%$ of the CCOs report to the General Counsel and 32\% to the CEO, whereas only $8 \%$ of them report to the Audit Committees (Compliance Week 2011). This substantially proves that the CCO is inserted in a direct, often dyadic relationship with the company's true power holders, if not with the CEO himself. It is important to notice, however, that the respondents felt this as a recent development, in particular within a picture of a generalized growing importance of corporate compliance, rather than a well established practice.

Increased power may bring, however, the disgraceful taste of a bitter fruit for the young officers. The admissions that "too much power creates barriers" $(\mathrm{Pal})$, or that "it is impossible to avoid feeling different when they know that you could denounce them one day" (Janos, 44) clearly show the other side of the coin. Compliance is not only empowering job figures that, until recently, were almost irrelevant to the companies, but it is putting emphasis on new qualities that are in a open conflict with the demands of compliance itself. This is what some of the respondents named "human factor", often with different and apparently conflicting views of the application of this idea.

Margit provides a good example. She has been working for a multinational over the last 5 years. She gained experience and received training in foreign branches before going back to Hungary, where the compliance program had just been adopted. The company in which she works has a complex compliance system, in which the headquarter sets its standards, and the Hungarian branch depends on another regional centre for Central Eastern Europe for the reporting system. Thus there are three actors in the compliance mechanisms, and their interaction, is, as it can be easily guessed, not always smooth. Margit has indicated the importance of the "human factor", which she expressed as the ability of the compliance officer to understand "motivations of the employees and managers" by "being as close as possible to them, in an empathic relation". This sort of empathy is exactly what theorists of integrity in business, following the above mentioned rational standpoint, denounce as perilous for the true implementation of compliance mechanisms.

Margit pointed out how for her job task freedom of developing interactional and judgment skills are paramount. However, introduction of the triangular reporting system seriously hampers this process, putting, in a counterintuitive manner, emphasis on empathic rather than on "rational" procedures. Because the double reporting system ends up with abstracting the Hungarian company from the compliance mechanisms, Margit is seen as a real power-holder, who communicates directly with both the main and the regional headquarters. Hence she feels an impellent need to increase trust relationships within her Hungarian company. Trust is according for her of pristine importance, but this means "being visible, showing yourself", whereas increasing bureaucracy in the compliance system may decrease trust, by introducing the menace of external actors taking decisions. Hence, she felt that one of the ways not to loose her attachment to the company she physically works with is to add emphasis on personal relations and interaction, which can easily endanger the rationality and impartiality of the compliance tasks.

\section{POWER THROUGH COMMUNICATION}

The second issue that is directly related with how to deal with the drawbacks of increased power of the compliance officers concerns the forms of communication they choose to adopt in the companies. Compliance programs are set in similar ways in the five companies I have studied. There is a general section dedicated to training, which is accompanied by the preparation of manuals. Afterwards, more targeted trainings may be applied to those sectors that are more sensible to cases of loss of integrity, as well as periodical refreshment training sessions. After these, apart from investigations that are specific and occur on occasional bases, the second main instrument through which compliance is enacted is the use of hotlines (by some called help-lines), see below. Both these forms need to be communicated to employees and managers.

Intuitively, the crucial requirement for a good compliance officer is a good skill of communication in two areas: the first is how ethical behavior is transmitted, and the second how compliance officers establish communication with high-level managers. Concerning the first, evidence from the interviews shows that the main difficulty is encountered when compliance personnel presents cases of company 
misconduct. In a small country as Hungary any case which presents the example of an unnamed company dealing with some form of legal exposure, can be potentially traced providing disclosure of the company and even of its employees involved. The idea is that giving names is avoided in training and case studies' sessions, if only because among managers there can be friends, acquaintances or even relatives involved from other companies.

On the other hand, the general recognition by 5 of the 6 respondents is that cases are of crucial importance for communicating the contents of compliance. They are useful for seeking "active participation in training", for "influencing and determining the mindset of company personnel", for "shocking and providing evidence at the right moment", or for complementing the "abstract force of corporate values". Hence, the use and choice of such cases, as well as the ways in which they are communicated (omitting or not some particular details, for instance) when left to the compliance officers, is another factor that can influence their power relations within the company. This happens, to follow Wolf (2003), not because of the capacity of the compliance personnel to exert power directly. The main issue here is that the environment in which power flows is very sensitive (due to the relatively small number of domestic companies, and also to the fairly high number of cases of loss of integrity in the region) to information and communications strategies.

The second, and even more delicate, issue concerns communication with superiors. On this point I received rather scattered answers which clearly reflect the context-dependence of this problem. Two of the interviewed expressed no difficulty in dealing about integrity with high-level managers, explaining that when the company commitment to compliance program is enough solid this constitutes a general anchor both in terms of corporate codes of conduct and of strategy. In this case, corporate values are an efficacious instrument "particularly if written somewhere" (Pal) that may shield senior managers who have been responsible for setting up and implementing such values. On the other hand, four more respondents emphasized how their task is particularly difficult when dealing with senior managers, who are not used to be directed. In such cases, the true challenge is individuated by the interviewed officers in the style of communication, and in the ways of maintaining personal relations within the company.

As Katalin clearly stated, "you cannot do things from above if you are not among them". Also, Janos pointed out that "a good CCO should know how to address different job roles with different forms of communication, examples, words and even cases". It is difficult, from the results of this ethnographic research, to judge whether the challenges that relate to the new forms of power that compliance mechanisms introduced in the companies can be applied to other regional business environments, since these data are specific of the Eastern European context. There is need for more research on this. However, some final indications on this point may emerge from the difficult relationship between legal and compliance departments that is perceived as a general challenge for compliance mechanisms worldwide, but has its own cultural peculiarities in the regions of application (Compliance Week 2012).

\section{THE LEGAL-COMPLIANCE SECTORS DIVIDE: THE CASE OF HELP-LINES}

As indicated above, historically the first steps of compliance were taken within the companies' legal departments or offices. This has changed through the years, as increased emphasis on compliance has moved companies to enhance their compliance programs through hiring of dedicated (even if not necessarily trained) personnel. The new factor emerging out of the interviews is that a thorough knowledge of legal issues is not exactly what compliance officers are expected to possess. Janos, stressed how "a good knowledge of financial risks, nowadays, is more important than one on legal matters in a good compliance system". Similarly, Pal indicated how in his company legal experts are often externals and not members who directly deal with compliance. This generates a sort of separation, which in the compliance literature is sometimes envisioned as positive (Watson 2003, Barrentine 2012). This divide, in reality, potentially underscores the true essence of compliance creating a sort of buffer zone between management and legal specialists involved in the interpretation and application of existing laws and regulations. In this zone, compliance officers may take the lead in dealing with communication of issues that can be too abstract or sensitive to be communicated by legal officers to employees and mid-level 
managers. One example of this divide concerns the use of hotlines as instruments for gathering denounces, suspects and concrete cases of whistle-blowing, but also for providing guidance in legal matters.

All the interviewed officers indicated the importance of hotlines, but also the difficulty of dealing with them in their companies. In only one company are compliance officers directly involved in the hotlines, whereas the preferred pattern is to have external legal consultants who work in them. This may be surprising, but it actually tells the difficulty of treating the legal issues, which are in many cases difficult for the compliance personnel itself who are not trained as attorneys. More significant, however, is that this difficulty is telling of the delicate "power game", or as Katalin defined it of a "prisoner's dilemma" being played in the companies. The compliance officer is aware that his role, and for extension his power in the company, squarely depends on the means through which he seeks legitimacy.

The whistle-blowing system, which works more or less effectively according to the differences in the socio-cultural contexts, is a poor tool in most of Eastern European countries, as indicated unanimously by all respondents. The point is not that in this region comparatively high exposure to corruption scandals has decreased trust and increased suspicion in whistle-blowing. The issue is that whistle-blowing was a common and infamous practice under state socialism: this practice served to maintain the power of totalitarian regimes through the double threat of suspicion/distrust, and the collection of a conspicuous amount of confidential information on citizens. Pal indicates this as follows: "In a country where the mindset of common people has been influenced by those who lived under such a system whistle-blowing simply doesn't work". Also Janos, who is a true believer of the efficacy of help-lines, is ready to recognize that "it is better for the CCO not to be involved in their implementation at all, otherwise his trustworthiness in the company is potentially destroyed".

If the system is deemed to work more or less efficiently, the operators of the hotlines need to be as distant as possible from the company, in order to shield the delicate role of the compliance officer. Hence, even the apparently innocuous task of legal advising is preferably outsourced, as well as the compliance officer is not required to be a legal specialist, but a good communicator if not even an expert of (personnel) managerial strategies.

\section{CONCLUSION}

Compliance is a field that has recently achieved increasing complexity and significance in business. As all forms of control and implementation of ethical behavior in the business sector, it is exposed to a number of challenges that in certain cases generate paradoxical conditions. One of these is the tension between increasing power of the compliance officers within the company's organizational structure, and the still undefined style and directions of the reporting system. Another evident paradox concerns the need to rationalize the compliance efforts, also according to more sophisticated legislative regulations worldwide, and the real life tasks and roles of these figures, suspended into webs of personal relations that they have, willing or unwilling, to manage.

This study has provided an ethnographic perspective, analyzing some of the daily challenges of compliance officers in six companies. From the interviews a number of points have emerged that confirm the existence of the paradoxes indicated above. What I find most relevant, however, is the idea that rather than providing companies with accountable and transparent instruments for complying with regulations, these job figures are achieving increased power that is demanding of particular strategies to manage it. What some of the interviewed have expressed is a general concern about loss of interpersonal trust, which their task causes in the companies.

Stronger power of the compliance officers is one of the recent developments that correlate with the increased needs of companies worldwide to establish and have in function compliance departments and mechanisms. If this is commonly saluted as a positive trend in the specialist literature on business ethics and integrity, it has a number of drawbacks particularly in the case of Hungary, described in this paper. Due to a number of social and cultural conditions (diffusion of informal practices, higher levels of interpersonal than generalized trust, suspicion and mistrust of whistle-blowing practices) compliance 
mechanisms need to be optimally paired with a true and thorough understanding of human motivations, forms and mechanisms of interpersonal communication and social interaction. The increased power of the compliance officer is an expression of these conditions, which may be at odd, in other regional contexts, with the theoretical groundings of corporate compliance itself.

\section{REFERENCES}

Ardichvili, A. and Jondle, D. (2009). Integrative Literature Review: Ethical Business Cultures: Review and Implications for HRD, Human Resource Development Review 8(2): 223-44.

Baer, M.H. (2009). Governing Corporate Compliance, Boston College Law Review 50: 949-1019.

Barrentine, G.P. (2012). The Emerging Role of CCOs in Risk Management, The Investment Lawyer 19 (2): $3-10$.

Bartlett, D. (2003). Management and Business Ethics: a Critique of Ethical Decision-Making Models, British Journal of Management 14(3): 223-35.

Brenkert, G.G. (2010). The Limits and Prospects of Business Ethics, Business Ethics Quarterly 20(4): 703-9.

Cefkin, M. (ed.) (2011). Ethnography and the Corporate Encounter. Reflections on Research In and Of Corporations, Oxford: Berghahn.

Cortina, A. (2008). Corporate Social Responsibility and Business Ethics. In J. Conill, C. Luetge and T. Schonwalder-Kuntze (eds) Corporate Citizenship, Contractarianism and Ethical Theory. On Philosophical Foundations of Business Ethics. Farnham, UK.: Ashgate, 69-78.

DeGeorge, R.T. (1990). Business Ethics, New York: Macmillan.

Gledhill, J. (2000). Power and Its Disguises. Anthropological Perspectives on Politics, London: Puto Press.

Jodan, N.T. (2010). The Importance of Business Anthropology: Its Unique Contributions, International Journal of Business Anthropology 1(1): 15-25.

Kurtz, D.V. (2001). Political Anthropology: Paradigms and Power, Westview: Boulder.

Moeran, B. (2005). The Business of Ethnography. Strategic Exchanges, People and Organizations, Oxford: Berg.

Pardo, I. (ed) (2004). Between Morality and the Law: Corruption, Anthropology and Comparative Societies, Aldershot: Ashgate.

Randall, D.M. and Gibson, A.M. (1990). Methodology in Business Ethics Research: a Review and Critical Assessment, Journal of Business Ethics 9(6): 457-71.

Schensul, S., Schensul, J. and LeCompte, M.D. (1999). Essential Ethnographic Methods. Observations, Interviews and Questionnaires, Walnut Creek, CA.: Altamira.

Shakeel, M, Khan, M.M. and Khan, A. M. (2011). "Impact of culture on business ethics". Far East Journal of Psychology and Business 3(2): 59-70.

Sharpe, D.R. (2004). The Relevance of Ethnography to International Business Research. In R. MarschanPiekkari and K. Welsch (eds) Handbook of Qualitative Research methods for International Business, Cheltenham, UK: Edward Elgard, 307-25.

Tian, R.G., Lillis, M.P. and van Merrijk, A. (eds.) (2010). General Business Anthropology, Seattle: North American Business Press.

Tian, R.G., Zhou, D. and van Merrijk, A. (eds.) (2011). Advanced Readings in Business Anthropology, Seattle: North American Business Press.

Torsello, D. (2003). Trust, Property and Social Change in a Southern Slovakian Village, Munster: Lit.

Torsello, D. (2012). The New Environmentalism? Civil Society and Corruption in the Enlarged EU, Farnham, UK.: Ashgate.

Tsalikis, J. and Fritzsche, D.J. (1989). Business Ethics: a Literature Review with a Focus on Marketing Ethics, Journal of Business Ethics 8(9): 695-743. 
Trevino, L. and Nelson, K. (2004). Managing business ethics: Straight talk about how to do it right, New York: Wiley.

Van Marrewijk, A. (2010). European Developments in Business Anthropology, International Journal of Business Anthropology 1(1): 26-44.

Vogel, D. J. (2005). Is There a Market for Virtue? The Business Case for Corporate Social Responsibility, California Management Review 47(4): 19-45.

Waddock, S. (2006). Forging a Path for Ethics and Business in Society, Academy of Management Learning \& Education 5: 334-345.

Watson, S. (2004). Fostering Positive Corporate Culture in the Post-Enron Era, Transactions The Tennessee Journal of Business Law 6:7-45.

Wolf, E. (2002). Facing Power - Old Insights, New Questions. In J. Vincent (ed.) The Anthropology of Politics. A Reader in Ethnography, Theory and Critique, Oxford: Blackwell. 